\title{
PROCEDIMENTOS METODOLÓGICOS PARA SE ELEGER CATEGORIAS DE ANÁLISE BASEADAS EM REFERÊNCIAS TEÓRICO-CONCEITUAIS
}

\author{
Methodological procedures to elect analytical categories based on theoretical and \\ conceptual references
}

\section{Procedimientos metodológicos para elegir categorías de análisis basadas en referencias teórico-conceptuales}

\author{
Bryann Breches* \\ Vanda Mendes Ribeiro** \\ Claudia Lemos Vóvio*** \\ Célia Maria Haas****
}

\section{Resumo}

Este artigo propõe procedimentos metodológicos para a definição de categorias de análise apriorísticas com base em referências teórico-conceituais. Foram elaboradas para o exercício de examinar um conjunto de entrevistas realizadas com professores da educação básica sobre suas percepções de formação continuada vivenciada ao longo de suas carreiras. Primeiramente, realizou-se levantamento de referências publicadas a partir de 2000, sobre formação continuada, junto ao Scielo, no ano de 2014. Em seguida, fez-se análise desses textos com base em orientações técnicas da análise de conteúdo. Requisitos comuns considerados, nessas referências, relevantes para a formação continuada docente constituíram categorias de análise apriorísticas.

PALAVRAS-CHAVE: Metodologia de pesquisa. Formação continuada. Categorias de análise.

\section{Abstract}

This article proposes a set of methodological procedures for the definition of a priori analytical categories on the basis of theoretical and conceptual references. These categories were then employed in the examination of a set of interviews with basic education teachers about their perceptions of a continued formation in their careers. In 2014, published references were raised from SciELO covering all the period from 2000 onwards on the topic of continuous formation. After that, an investigation was made of these texts following technical orientations of content analysis. Common relevant requisites for continuous teacher's formation were picked up in the references, which enabled the establishment of analytical categories.

\section{KEYWORDS: Research methodology. Continuous formation. Analytical categories.}

\footnotetext{
* Mestre em Educação pela Unicid. Agente Comunitário de Saúde de Campos do Jordão. E-mail: bryannbreches@gmail.com

** Mestre em Sociologia pela Unicamp, Doutora em Educação pela Feusp. Professora dos Programas de Pósgraduação em Educação e Educação Profissional da Unicid. E-mail: vandaribeiro2@gmail.com

*** Doutora em Educação pela Unicamp. Professora Adjunta do Departamento de Educação da Unifesp. E-mail: claudiavovio@gmail.com

**** Doutorado em Educação pela Puc-São Paulo. Professora dos programas de Pós-Graduação em Educação e Educação Profissional da Unicid. E-mail: celiahaas1@gmail.com
} 


\section{Resumen}

Este artículo propone un conjunto de procedimientos metodológicos para la definición de categorías de análisis apriorísticos con base en referencias teórico-conceptuales. Esas categorías fueron empleadas para el ejercicio de examinar un conjunto de entrevistas realizadas con profesores de educación básica respecto a sus percepciones de formación continuada vivenciada a lo largo de sus carreras profesionales. Se ha realizado levantamiento de referencias publicadas a partir de 2000, sobre formación continuada, junto al Scielo, en el 2014. Luego, se ha hecho análisis de esos textos con base en orientaciones técnicas de análisis de contenido. Requisitos comunes considerados, en esas referencias, relevantes para la formación continuada docente constituyeron categorías de análisis apriorísticos.

PALABRAS-CLAVE: Metodología de pesquisa. Formación continuada. Categorías de análisis.

\section{INTRODUÇÃO}

Este artigo apresenta o percurso metodológico que permitiu a definição de categorias de análise apriorísticas, estabelecidas com base em referências teórico-conceituais, para interpretação de dados advindos de entrevistas com professores numa escola de contexto de alta vulnerabilidade social, acerca da formação continuada que realizaram ao longo de sua carreira docente. Para tanto, fez-se necessário o uso de categorias de análise para a compreensão dos dados. Conforme Duarte (2004, p. 221) "as categorias de análise podem ser eleitas pelo pesquisador antes da realização das entrevistas [...], a partir de referências teórico/conceituais [...]".

Para se chegar a relevantes referências que pudessem oferecer um conjunto de categorias apriorísticas legítimas na área da educação foi feito levantamento, no primeiro trimestre do ano de 2014, na base Scielo, com as seguintes palavras-chave: formação continuada, formação permanente, formação contínua e formação de professores. Foram selecionados, pela leitura dos resumos, os artigos pertinentes. Alguns livros usados nesses artigos foram incluídos para análise.

A literatura foi estudada, considerando-se orientações técnicas da análise de conteúdo, com base em Bardin (1977), buscando requisitos que se repetem nos textos dos especialistas e que poderiam se constituir em elementos significativos para a compreensão dos discursos dos professores entrevistados sobre formações continuadas.

A análise de conteúdo, para Bardin (1977), é uma técnica para identificar "a presença ou ausência de uma dada característica de conteúdo ou de um conjunto de características num determinado fragmento de mensagem" (BARDIN, 1977, p. 21, grifo do autor), sem necessariamente encerrar-se numa métrica de frequências, mas pode, com a contribuição de diversos saberes, alcançar o entendimento de elementos significativos da comunicação. Para a autora (1977), a categorização possui duas etapas. A primeira, refere-se ao isolamento dos elementos da comunicação - desmembramento do discurso em unidades de sentido e a segunda, trata-se da classificação dos elementos em grupos, a partir de uma certa organização das mensagens.

A definição das categorias de análise apriorísticas exigiu dois momentos distintos. O primeiro foi de seleção das referências pertinentes. Esse caminho partiu da definição de palavras-chave para busca de referências e do estabelecimento do período no qual as 
publicações seriam de interesse, para se fazer a busca, passando pelo levantamento de referências e leitura dos resumos, até a identificação dos artigos pertinentes, bem como livros usados nesses artigos. A partir da identificação das referências pertinentes, passou-se ao segundo momento, de estudo dos textos escolhidos, considerando que as mensagens desses textos teriam elementos indispensáveis para a compreensão da percepção dos professores sobre formações continuadas das quais participaram. Para o estudo das referências, recorreuse a cinco procedimentos: 1) identificação de requisitos que cada referência considera centrais para uma formação continuada efetiva; 2) classificação, por meio de interpretação, dos requisitos comuns entre distintas referências; 3) formulação de meta-requisitos que abarcam, por proximidade temática, um conjunto de requisitos apontados pelas referências utilizadas; 4) apontamento de tais meta-requisitos como possíveis categorias de análise apriorísticas; e 5) identificação dos meta-requisitos mais fortes, apontados por um maior número de referências, que seriam aquelas usadas para a análise das entrevistas.

Antes do detalhamento dos procedimentos metodológicos acima apontados, faz-se necessário apresentar as ideias centrais apreendidas das referências utilizadas e que serviram de base para se chegar aos requisitos e meta-requisitos que se transformaram nas categorias apriorísticas de análise.

\section{Requisitos relevantes para a formação continuada: temas e orientações advindos das referências analisadas}

Segundo Fusari (1992), discutir a formação dos professores significa situar a realidade no contexto mais amplo da democratização do ensino e da sociedade. A importância da discussão da formação dos professores não resolve a questão da democratização, mas é de suma importância para a construção de uma escola acessível, de qualidade e que cumpra com a sua função social. $\mathrm{O}$ autor indica cinco aspectos relativos à competência docente como necessários para o desenvolvimento profissional: o domínio competente e crítico do conteúdo a ser ensinado, a clareza dos objetivos a serem atingidos junto aos alunos, o domínio competente dos meios de comunicação a serem utilizados para a mediação eficaz entre o aluno e os conteúdos do ensino, a visão articulada do funcionamento da escola como um todo e a percepção nítida e crítica das complexas relações entre educação escolar e sociedade. Afirma ainda, que se faz necessário não considerar a docência como uma competência inata, um dom, num contexto pronto, estático. Os professores devem ser estimulados a uma busca contínua de desenvolvimento profissional.

Nóvoa (1995) tece considerações sobre formação docente a partir das transformações do ensino em Portugal que, para ele, passou da tutela da Igreja, para o Estado. O Estado seria legítimo para regular uma importante área de reprodução social, a formação dos agentes responsáveis pelo ensino. O autor afirma que os processos de formação inicial e a profissionalização em serviço estão em fase de amadurecimento, sendo a formação continuada um foco de atenção.

Conforme esse autor, os professores devem ser protagonistas nas fases que compõem os processos de formação, tanto na concepção, quando no acompanhamento, regulação e avaliação e reconhece que a formação de professores é um momento importante de socialização. Para Nóvoa (1995), as práticas de formação contínua dos professores devem 
tomar uma dimensão coletiva, visando contribuir para a emancipação profissional e para a autonomia na produção de saberes e valores, sendo o diálogo entre os professores fundamental para consolidar saberes da prática profissional. Alerta que a formação continuada se realiza por meio de um processo advindo da reflexão e criticidade, no qual se dá a constituição da identidade e da trajetória profissional.

Para Nóvoa (1995), a mudança sofrida pelo contexto educacional deve ser considerada na formação de professores, uma vez que, a formação continuada é processo permanente, envolvendo a realidade diária do professor, pois ao mesmo tempo em que o professor realiza o seu trabalho ele investiga, se forma, troca com seus pares, criando, dessa forma, um ambiente colaborativo.

Imbernóm (2009) afirma ser necessário abandonar o conceito de formação enquanto atualização científica e didática, estendendo o conceito de formação continuada para o terreno das capacidades, habilidades e atitudes. Para esse autor, os valores e as concepções de cada professor e de todos os profissionais da educação devem ser questionados permanentemente. A aquisição de conhecimentos ocorre de maneira interativa e está ligada à prática profissional e é condicionada pela organização da instituição educacional. Atualmente, além da necessidade de um novo olhar para a aprendizagem discente na relação com o trabalho docente, o professor necessita construir conhecimentos sobre sua prática profissional e conhecimentos dos valores, dando maior ênfase ao contexto e aos sujeitos inseridos no processo de ensino e aprendizagem.

Para Imbernón (2009; 2010), a formação permanente deve se basear na reflexão dos sujeitos sobre a sua prática, de maneira que o professor seja um construtor de conhecimento individual e coletivo. $\mathrm{O}$ autor estabelece cinco linhas de atuação na formação permanente:1) Reflexão teórico-prática; 2) A troca de experiências entre iguais; 3) A união da formação a um projeto de trabalho; 4) A formação como estímulo crítico e; 5) O desenvolvimento profissional da instituição educativa mediante o trabalho conjunto.

Silva (2000) discute o papel e a importância da reflexão para o desenvolvimento profissional e acredita que a discussão acerca da formação continuada ocorre em uma sociedade em constantes mudanças, onde novas demandas são postas para o professor, razão pela qual gera-se a necessidade permanente de reflexão. Silva (2000) destaca em sua pesquisa três modelos de formação continuada: 1) Transmissivo: orientado pela aquisição de conhecimentos e objetividade da realidade; 2) Racionalidade técnica e instrumental: Orientadas para os objetos que os professores deverão conhecer e manipular instrumentalmente; e, 3) O experiencial: centrado no processo de constituição da identidade e profissionalização do professor, que reconhece a subjetividade dos sujeitos envolvidos.

A respeito das perspectivas de formação de professores, Candau (2003) destaca que não são encontradas em um estado puro e propõe, pelo menos, duas. A primeira é a perspectiva clássica. A perspectiva clássica tem, para a autora, ênfase na atualização da formação recebida, no processo de reciclagem, tratando-se de atividades construídas e mantidas pela tradição. Segundo ela, esta tendência é a mais utilizada e promovida nas secretarias municipais e estaduais de educação. Afirma ainda que a perspectiva clássica pode assumir diferentes modalidades: convênios entre secretarias e universidades; cursos promovidos pelas secretarias; convênios entre escolas e empresas; cursos presenciais e à distância.

A outra são novas tendências, sob três modalidades. A primeira considera a escola como lócus da formação continuada, local de reflexão acerca da prática docente. A segunda 
considera a relevância dos saberes que possuem os professores. Por fim, a terceira, refere-se ao ciclo de vida dos professores e sua trajetória profissional. Candau (2003) conclui que, nos processos formativos, é necessário articular, dialeticamente, as diferentes dimensões da profissão docente, sendo estas as dimensões ética, cultural, social, ideológica, científica, política, superando as abordagens clássicas.

Chamon (2006) pesquisou "como uma formação pode ser ao mesmo tempo válida no plano epistemológico e útil no plano socioprofissional”. Aplicou um questionário junto a 250 professores, dos quais retornaram 189. A pesquisa foi realizada com Professores do Ensino Básico I (PEB I) do Estado de São Paulo, inseridos no Programa de Educação Continuada (PEC), programa que foi desenvolvido sob a infraestrutura dos Centros Específicos de Formação e Aperfeiçoamento do Magistério (CEFAMs). Uma das questões do questionário tratou sobre "o que é formação PEC". Os resultados apontaram que a formação:

- Gera aquisição de novos conhecimentos (95\%): a formação continuada é uma fonte relevante na construção dos saberes docentes acerca de sua prática;

- $\quad$ Permite a melhoria da prática em sala de aula (92\%): alto percentual que considera a formação continuada enquanto uma ação necessária ao desenvolvimento de competências que deverão ser utilizadas na prática;

- $\quad$ Permite trocar informações com os colegas de profissão (85\%): a troca entre pares é dimensão relevante da formação continuada dos professores.

Para Brzezinski (2008), há, no Brasil, um imaginário que classifica a formação continuada como um meio de sanar lacunas da formação inicial. Afirma que a formação continuada de professores deve ser uma práxis, concretizada em uma articulação entre teoria e prática, no qual o saber é multidisciplinar e a prática unodocente, numa articulação de saberes pedagógicos, culturais e políticos.

Para Pinto (2008) é necessário dedicar atenção à orientação dos professores, por meio de uma formação que priorize a relação teoria-prática, em um espaço de construção coletiva de conhecimento, favorecendo o processo de ensino-aprendizagem, ampliando assim, o sucesso na aprendizagem discente.

Gatti (2003) tratou das condições sob as quais mudanças da ação profissional dos professores podem ocorrer como fruto de um programa de formação em serviço, indicando que os processos formativos devem estar integrados à ambiência em que os profissionais atuam. A autora afirma que um professor é uma pessoa com uma história; um ser social que possui identidade pessoal e profissional, estando inserido em uma vida grupal. Dessa instância grupal advêm, segundo Gatti (2003), seus conhecimentos cuja assimilação depende de eventos sociais e culturais. Esses eventos dizem respeito aos contextos em que estão inseridos os docentes no processo de formação, atrelados às representações culturais, às questões de ordem política, econômica, à visão de educação, à concepção de prática pedagógica. Além disso, há também a experiência que é intrínseca a cada sujeito. O professor pode ser, devido a essa experiência, acessível ou resistente ao processo de formação. De acordo com a autora, para agir, as pessoas consideram tanto elementos contidos nas representações sociais e culturais (fatores externos) quanto o que concerne à sua individualidade enquanto sujeito (fatores internos). Para Gatti (2003), é simplista a ideia de que melhorar o rol de conhecimentos do professor resultará, necessariamente, em mudanças nas práticas docentes e, consequentemente, no contexto escolar. Conclui que, para ocorrerem mudanças nas concepções e práticas educacionais docentes, é necessário que os programas implementados considerem a ambiência psicossocial e cultural em que os sujeitos estão inseridos. 
Gatti e Barreto (2009) realizaram balanço da situação formativa dos professores brasileiros, refletindo sobre as condições de trabalho, legislações, salário, condições dos cursos de formação de professores. As autoras afirmam que surgiu, na área educacional, um novo paradigma acerca da formação continuada: que valoriza o sujeito professor e passa a levar em conta o seu protagonismo, a representação e o contexto onde estão os desafios reais e inerentes à profissão. Destacam que, no Brasil, há uma valorização de cursos de formação continuada pelas redes de ensino e por parte dos professores no que diz respeito à perspectiva de desenvolvimento profissional e também visando a melhoria do ensino e do desempenho dos alunos. As autoras alertam, entretanto, que os processos formativos efetivos nem sempre conseguem efetivar o referido paradigma. Afirmam que os professores estão submetidos a políticas ou programas de formação continuada dos quais não participam como agentes. Muitas vezes, os profissionais formadores que atuam nessas formações não têm conhecimento da conjuntura escolar dos professores participantes. Há falta de apoio aos professores, segundo as autoras, durante o processo de formação continuada, tornando inviável fazer uma relação entre o programa oferecido e o contexto escolar, porquanto, os professores têm dificuldades em desenvolver novas ações após o término dos programa formativos, não consolidando os avanços. Para elas, esse quadro é piorado pelo fato de que as políticas públicas educacionais são descontínuas.

As autoras tratam da necessidade de uma articulação entre a formação inicial, a continuada e os estágios de formação continuada de modo a contemplar a diversidade da trajetória profissional dos professores. Para tanto, seria necessário haver uma aproximação entre as agências formadoras e a realidade escolar; observar o que os professores pensam e sabem acerca da formação; e conhecer as estratégias de acesso aos bens culturais dos professores. Concluem que o que tem se mostrado efetivamente é uma formação com foco em conteúdos disciplinares.

Davis et al. (2011) estudou ações de formação continuada nos estados e municípios brasileiros, envolvendo 19 secretarias estaduais e 13 secretarias municipais das cinco regiões brasileiras. Foram entrevistados secretários de educação, coordenadores e responsáveis pelos programas de formação continuada destas secretarias. As autoras apontaram a existência de duas perspectivas: as individualizadas e as colaborativas. As perspectivas individualizadas buscam valorizar o docente, considerando o ciclo de vida e o desenvolvimento profissional. As perspectivas colaborativas estão relacionadas com as vivências na escola, a troca entre os pares, o papel do coordenador pedagógico como formador de professores e articulador de ações de formação continuada de professores.

Segundo Imbernóm (2009) é necessário abandonar o conceito de formação continuada enquanto atualização científica e didática, estendendo o conceito para o terreno das capacidades, habilidades e atitudes. Os valores e as concepções de cada professor devem ser questionados permanentemente, porque a aquisição de conhecimentos ocorre de maneira interativa e está ligada à prática profissional e é condicionada pela organização da instituição educacional. Para Imbernón (2010), a partir dos anos 1990, irá surgir um maior acervo de literaturas sobre formação continuada de professores, quando ocorreram também divergências sobre modelos pautados no treinamento do docente. A partir dos anos 2000 até os dias atuais, percebem-se novos processos econômicos, embasados pelo crescimento tecnológico, dentre outros fatores, que irão influenciar na formação dos professores. Trata-se, para o autor, de um período de grandes crises uma vez que a instituição educativa necessita renovar o seu 
currículo para educar frente a novas demandas, novas formas e maneiras de articular o conhecimento e a aprendizagem, com o reconhecimento de emoções e valores dos sujeitos.

$\mathrm{O}$ autor ainda afirma que a identidade docente corresponde à "trajetória ou desenvolvimento profissional" e é necessário que o professor deixe de ser considerado enquanto objeto da formação continuada para que este se torne o seu sujeito (IMBERNÓN, 2010, p. 80). A escola é cercada por um espaço comunitário, composto por sujeitos históricos pertencentes a uma realidade social que deve ser considerada ao discutir a formação continuada de professores, considerando a conjuntura social na qual o professor desempenha o seu trabalho.

Tardif (2014) reconhece a especificidade do trabalho docente, diferenciando o trabalho produtivo, do social. No trabalho produtivo, o trabalhador possuirá um maior controle de seu objeto de trabalho. De acordo com o autor, um trabalhador industrial possui controle de seu objeto de trabalho, ao passo que um professor necessita ter interação com seu objeto, visto que um docente exerce sua prática profissional junto a sujeitos, que são seres humanos individuais e sociais. Sendo assim, a ação do professor é uma "interação humana", o que gera uma complexidade acerca do exercício profissional, fazendo com que os objetivos de seu trabalho dependam de "ações, decisões e escolhas". Afirma que durante muitos anos, a escola foi moldada a partir dos conhecimentos do sistema de produção, pautados sobre a teoria da proletarização. A escola, além de ser colocada como sendo periférica e secundarizada à esfera produtiva e mercadológica, é também moldada sob aspectos fabris: um espaço, várias crianças, o conhecimento, a avaliação, tornando burocratizada uma série de relacionamentos. Para o autor, trata-se de relacionamentos, uma vez que o processo educativo envolverá sujeitos e não produtos, e desta forma urge a necessidade de novos paradigmas para a esfera do trabalho educacional.

Para Tardif e Lessard (2014), o professor interage com todos os atores da escola onde atua. Avaliam que o objeto de trabalho do professor consiste em interações humanas. Nessas interações, o objetivo do trabalho do professor é a transformação de sujeitos, que constroem significados e reagem numa cultura social. De acordo com os autores, a instrução sempre foi um elemento necessário para a evolução dos sujeitos nos diferentes momentos históricos. Da interação depende o processo de escolarização de um sujeito que não acontece apenas na escola, mas está presente em outros âmbitos: o familiar, o profissional, o científico, o artístico, o político, dentre outros. Porém, a educação escolar, para os autores, é secundarizada em uma sociedade que valoriza os meios de produção, fazendo da educação escolar apenas algo para se chegar às relações do trabalho profissional. E, nessa esfera, o trabalho docente está subordinado à produção mercadológica. Desse modo, os estudantes de hoje são os trabalhadores de amanhã, ocorrendo um processo de reprodução da desigualdade social. A escola seria uma agência repressiva e reforçadora de desigualdades na base, composta por agentes de reprodução sociocultural. Na organização do trabalho escolar, além do docente, existem outros atores que atuam neste mesmo local e estruturas internas e externas que interferem no trabalho do professor. Os elementos que influenciam e caracterizam o trabalho docente, para os autores, são: o local de trabalho, nesse espaço é definido o trabalho docente, sua realização, seu planejamento, sua remuneração e sua percepção por parte da sociedade; as rotinas organizacionais, produtos de convenção histórica e social, manifestados em rotinas, uma vez que, cada escola, tem a sua forma de organização que se mantém ao longo do tempo, e os objetivos simbólicos, materialmente intangíveis, abrangendo as dimensões da essência (ser), do trabalho (fazer) e do saber (conhecimento). 
Ainda em Tardif e Lessard (2014), percebe-se que o trabalho docente não se limita aos resultados da aprendizagem discente, mas engloba um processo de modificação e aprendizagem do trabalhador, que age sob uma determinada realidade escolar e para um grupo de alunos que se apresenta de maneira heterogênea. Para eles, deve ser reconhecido o trabalho que o professor realiza e também o local onde ele trabalha e o sujeito para quem ele ensina.

Tardif $(2000$; 2014) trata dos saberes mobilizados para a ação docente, relevantes então para a formação continuada: os saberes sociais, produzidos por uma determinada cultura ou um conjunto delas; os saberes profissionais, que se constituem dos constructos da ação profissional, os saberes institucionalizados, e os saberes dos professores, inerentes à formação e profissão docente e os saberes disciplinares, assim como os da prática. O autor (2000) mostra que os saberes dos professores são temporais, pois abrangem toda a história do docente enquanto indivíduo, as próprias reflexões, a educação escolar, a formação inicial, seu ingresso e a história na carreira. Para ele, os saberes dos professores são plurais e heterogêneos porque existem diversas fontes nas quais os professores se apoiam, sendo essas a cultura pessoal, a cultura escolar, os conhecimentos didáticos, disciplinares, pedagógicos e os conhecimentos curriculares, formando um repertório variado de conhecimentos. Os saberes dos professores são personalizados e situados uma vez que o professor é um ator social e tais saberes são utilizados em função de uma situação específica, sendo necessária a formação continuada.

Para Tardif (2014), os saberes são hierarquizados pelos professores. Quando um determinado saber é utilizado com maior frequência, maior relevância terá, como o caso dos saberes adquiridos na experiência. Um dos requisitos da formação continuada dos professores, para o autor, é a importância de conhecer a realidade educacional. Assim, podem ser identificados fatores fundamentais da experiência cotidiana na escola. Tardif e Raymond (2000, p. 217) afirmam que boa parte do que os professores sabem sobre o ensino advém de sua trajetória pré-profissional. O professor traz consigo experiências e conceitos de sua trajetória escolar para a sua prática profissional, pois, foi aluno e hoje atua como docente. Para os autores, os professores modificam pouco suas crenças na formação inicial e estando no contexto da urgência do ensino, mobilizam crenças advindas muitas vezes de sua experiência enquanto alunos. Para Tardif (2014, p. 291) os processos de formação contínua devem se concentrar "nas necessidades e situações vividas pelos práticos e diversifica suas formas: formação através dos pares, formação sob medida, no ambiente de trabalho, integrada numa atividade de pesquisa colaborativa".

\section{Compartilhando os procedimentos metodológicos para definição das categorias de análise}

A seguir, serão detalhados os procedimentos adotados na composição das categorias de análise. O primeiro foi a elaboração de um quadro que cruza cada referência com a síntese das ideias centrais trazidas por ela no que se refere aos requisitos considerados fundamentais para a formação continuada. Para se chegar à síntese de cada autor, fez-se leitura de cada texto, explicitando-se as mensagens centrais que diziam respeito a requisitos relevantes para a formação continuada. $\mathrm{O}$ quadro 1 apresenta esse primeiro procedimento. 
Quadro 1 - Categorias acerca da formação continuada.

\begin{tabular}{|c|c|}
\hline Autor & Requisitos relevantes, segundo as referências analisadas \\
\hline $\begin{array}{l}\text { Brzezinski } \\
(2008)\end{array}$ & $\begin{array}{l}\text { 1. Articular os saberes docentes e favorecer a relação entre teoria e prática. (I) } \\
\text { 2. Gerar conhecimento sobre as competências docentes. (D) }\end{array}$ \\
\hline Candau (2003) & $\begin{array}{l}\text { 1. Promover a escola como lócus da reflexão sobre a prática docente. (C) } \\
\text { 2. Considerar a relevância dos saberes que possuem os professores. (F) } \\
\text { 3. Considerar a relação entre prática e trajetória profissional docente. (F) } \\
\text { 4. Articular as diferentes dimensões dos saberes da profissão docente. (I) }\end{array}$ \\
\hline Chamon (2006) & $\begin{array}{l}\text { 1. Refletir sobre a melhoria da prática profissional na sala de aula. (C) } \\
\text { 2. Considerar a troca de informações entre os colegas. (B) } \\
\text { 3. Refletir sobre o trabalho em equipe. (E) } \\
\text { 4. Contribuir para o fortalecimento da identidade do professor. (G) }\end{array}$ \\
\hline $\begin{array}{l}\text { Davis et al. } \\
(2011)\end{array}$ & 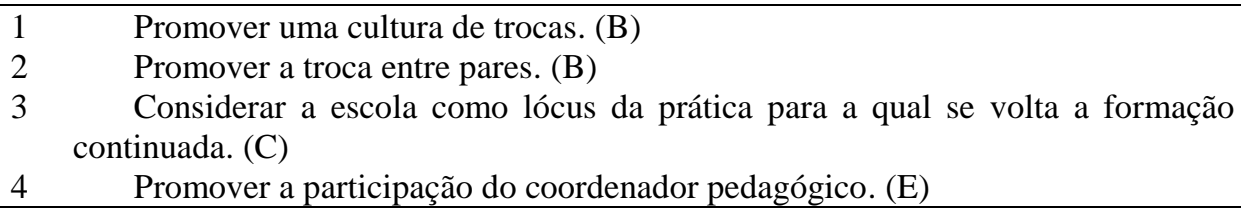 \\
\hline Fusari (1992) & $\begin{array}{l}\text { 1. Propiciar o domínio do conteúdo que o professor ensina. (D) } \\
\text { 2. Propiciar ao professor, clareza de seus objetivos. (D) } \\
\text { 3. Propiciar visão articulada do funcionamento da escola. (E) } \\
\text { 4. Gerar visão das relações entre educação e sociedade. (A) } \\
\text { 5. Compreender o ensino como algo que vai além de competências inatas. (D) }\end{array}$ \\
\hline Gatti (2003) & $\begin{array}{l}\text { 1. Integrar a ambiência em que os professores atuam. (C) } \\
\text { 2. Incluir a observação da prática do professor por tutor ou coordenador pedagógico. } \\
\text { (C) } \\
\text { 3. Considerar os aspectos socioafetivos e a individualidade dos sujeitos. (G) } \\
\text { 4. Considerar os contextos culturais que envolvem os professores. (G) } \\
\text { 5. Considerar que as práticas dos professores se relacionam com seus valores, crenças } \\
\text { e experiências. (F) } \\
\text { 6. Favorecer um ambiente colaborativo. (B) }\end{array}$ \\
\hline $\begin{array}{l}\text { Gatti e Barreto } \\
(2009)\end{array}$ & $\begin{array}{l}\text { 1. } \text { Gerar reflexão sobre a prática. (I) } \\
\text { 2. Valorizar a prática profissional. (C) } \\
\text { 3. Ter estratégias de fortalecimento institucional. (E) } \\
\text { 4. Considerar o contexto no qual age o professor. }(\mathrm{H}) \\
\text { 5. Considerar e valorizar o que os professores pensam e sabem sobre a educação. (F) } \\
\text { 6. Considerar a relação entre prática, saber e trajetória profissional. (F) } \\
\text { 7. Considerar as estratégias de acesso aos bens culturais dos professores. (G) } \\
\text { 8. Favorecer a troca entre pares. }(\mathrm{B})\end{array}$ \\
\hline $\begin{array}{l}\text { Imbernóm } \\
(2009,2010)\end{array}$ & $\begin{array}{l}\text { 1. Refletir sobre novas formas do trabalho docente. (A) } \\
\text { 2. Refletir sobre a importância da construção e articulação do conhecimento nos dias } \\
\text { atuais. (A) } \\
\text { 3. Compreender o contexto social em que os sujeitos estão inseridos. (H) } \\
\text { 4. Contribuir para que o professor seja considerado o sujeito da formação. (G) } \\
\text { 5. Unir o processo de formação à comunidade. (H) } \\
\text { 6. Promover reflexão sobre os valores. (F) } \\
\text { 7. Promover processos colaborativos e unir a formação a um projeto de trabalho. (B) } \\
\text { 8. Promover a união entre teoria e prática. (I) }\end{array}$ \\
\hline
\end{tabular}




\begin{tabular}{|c|c|}
\hline Nóvoa (1995) & $\begin{array}{l}\text { 1. Fortalecer a socialização. (B) } \\
\text { 2. Fortalecer a identidade profissional. (G) } \\
\text { 3. Contribuir para a emancipação e autonomia na construção de saberes e valores. (G) } \\
\text { 4. Propiciar diálogo entre os professores. (B) } \\
\text { 5. Ter os professores enquanto protagonistas na produção do conhecimento. (F) } \\
\text { 6. Ter uma dimensão coletiva em ambiente colaborativo. (B) } \\
\text { 7. Promover a reflexão e a criticidade. (I) } \\
\text { 8. } \\
\text { Envolver a realidade diária do professor. (C) }\end{array}$ \\
\hline Pinto (2008) & $\begin{array}{l}\text { 1. Priorização da relação teoria e prática. (I) } \\
\text { 2. Uso da construção coletiva do conhecimento. (B) } \\
\text { 3. Favorecer a aprendizagem discente. (D) } \\
\text { 4. Envolver a gestão escolar no processo de formação dos professores. (E) }\end{array}$ \\
\hline Silva (2000) & $\begin{array}{ll}\text { 1. } & \text { Considerar a trajetória profissional dos professores. }(\mathrm{F}) \\
\text { 2. } & \text { Considerar as novas exigências para a profissão docente. (A) } \\
\text { 3. Considerar a necessidade de permanente reflexão sobre a prática. }(\mathrm{C}) \\
\text { 4. } & \text { Reconhecer a subjetividade dos sujeitos envolvidos. }(\mathrm{G})\end{array}$ \\
\hline $\begin{array}{l}\text { Tardif }(2000, \\
2014)\end{array}$ & $\begin{array}{l}\text { 1. Considerar e articular os variados saberes dos professores. (I) } \\
\text { 2. Considerar a relevância do saber advindo da experiência do professor. (F) } \\
\text { 3. Considerar o conhecimento da realidade local. (H) } \\
\text { 4. Refletir sobre a produção e aplicação do conhecimento na prática. (D) } \\
\text { 5. Considerar que os objetivos dos professores dependem de ações, decisões e } \\
\text { escolhas nas situaçães concretas da prática. (C) } \\
\text { 6. Promover a formação por meio dos pares. (B) } \\
\text { 7. Promover a formação no ambiente de trabalho. (C) } \\
\text { 8. Integrar a formação em atividade de pesquisa colaborativa. (B) } \\
\text { 9. Considerar que o professor vive em um mundo em transformação. (A) }\end{array}$ \\
\hline $\begin{array}{l}\text { Tardif e } \\
\text { Raymond } \\
\text { (2000) }\end{array}$ & $\begin{array}{l}\text { 1. Considerar a trajetória pré-profissional dos professores e sua relação com a prática. } \\
\text { (F) }\end{array}$ \\
\hline $\begin{array}{l}\text { Tardif e Lessard } \\
(2014)\end{array}$ & $\begin{array}{l}\text { 1. Reconhecer que a profissão docente se realiza pela interação. (A) } \\
\text { 2. Reconhecer a complexidade da profissão docente. (A) } \\
\text { 3. Reconhecer o local em que se trabalha e os sujeitos para quem o professor ensina;. } \\
\text { (H) } \\
\text { 4. Realizar-se na relação com o lócus de trabalho. (C) } \\
\text { 5. Considerar as rotinas organizacionais e as questões simbólicas que envolvem a } \\
\text { instituição escolar. (E) }\end{array}$ \\
\hline
\end{tabular}

Fonte: Elaborado pelos autores.

Na sequência, buscou-se aproximações entre cada uma das mensagens. Foram geradas novas formulações, temáticas capazes de abranger mais de um requisito central presente em cada referência. Essas novas formulações, nominadas meta-requisitos, foram relacionadas a letras em maiúscula colocadas na frente de cada mensagem (requisito central), o que indica a proximidade temática entre requisitos presentes em diferentes referências, conforme é possível observar também no quadro 1. Portanto, as letras indicam meta-requisitos capazes de classificar os vários requisitos identificados em cada referência. Esse procedimento pode denotar proximidades e distanciamentos entre os requisitos. Ao todo, identificou-se nove distintos meta-requisitos (letras de A a I) para classificar as mensagens relevantes trazidas pelas referências, o que pode ser observado no quadro 2 . 
Quadro 2. Temas identificados para classificar os requisitos relevantes para efetividade da formação continuada

\begin{tabular}{|l|l|}
\hline Letras & Meta-requisitos elaborados a partir dos requisitos extraídos das referências \\
\hline A & $\begin{array}{l}\text { Promoção da compreensão das relações entre a sociedade, suas transformações e a } \\
\text { educação. }\end{array}$ \\
\hline B & Promoção da troca entre pares e do trabalho coletivo. \\
\hline C & Reconhecimento da relevância da prática do professor. \\
\hline D & Promoção do conhecimento sobre o que o professor ensina. \\
\hline E & Promoção de visão sobre o lócus onde se dá a prática do professor (instituição e equipe). \\
\hline F & $\begin{array}{l}\text { Valorização e reconhecimento dos saberes, valores, crenças, experiência e trajetória } \\
\text { profissional dos professores. }\end{array}$ \\
\hline G & Fortalecimento da identidade profissional do professor. \\
\hline H & Promoção da compreensão do contexto em que o professor, a escola e o aluno está inserido \\
\hline I & Articulação entre os variados saberes e relação entre teoria e prática. \\
\hline
\end{tabular}

Fonte: Elaborado pelos autores.

Em seguida, procurou-se observar quais autores se referiam a cada um dos metarequisitos. O objetivo era identificar aqueles que se fazem mais presentes nas referências analisadas. Essas seriam as mensagens mais fortes presentes no conjunto de textos selecionados e, por essa razão, seriam indicadas como categorias de análise apriorísticas para que, então, se pudesse proceder à análise das entrevistas realizadas com os professores.

O quadro 3 apresenta a relação entre os meta-requisitos e as referências, denotando a frequência com que mensagens de cada referência (requisitos de formação continuada) podem ser classificadas segundo os meta-requisitos.

Quadro 3 - Requisitos comuns de formação continuada

\begin{tabular}{|c|c|c|}
\hline $\begin{array}{l}\text { Meta-requisitos (que indicam } \\
\text { temas que classificam mensagens) }\end{array}$ & Autores & $\begin{array}{l}\text { Frequência de referências } \\
\text { que apontam mensagens } \\
\text { classificadas nos meta- } \\
\text { requisitos }\end{array}$ \\
\hline $\begin{array}{l}\text { Promoção da } \text { compreensão das } \\
\text { relações entre a sociedade, suas } \\
\text { transformações e a educação. (A) }\end{array}$ & $\begin{array}{l}\text { Fusari (1992), Imbernón }(2009,2010), \\
\text { Silva (2000), Tardif }(2000,2014) .\end{array}$ & 6 \\
\hline $\begin{array}{l}\text { Promoção da troca entre pares e do } \\
\text { trabalho coletivo. (B) }\end{array}$ & $\begin{array}{l}\text { Chamon (2006), Davis et al. (2011), } \\
\text { Gatti (2003), Gatti e Barreto (2009), } \\
\text { Imbernón (2009, 2010), Nóvoa (1995), } \\
\text { Pinto (2008), Tardif (2000, 2014) }\end{array}$ & 10 \\
\hline $\begin{array}{l}\text { Reconhecimento da relevância da } \\
\text { prática do professor. (C) }\end{array}$ & $\begin{array}{l}\text { Candau (2003), Chamon (2006), Davis } \\
\text { et al. (2011), Gatti (2003), Gatti e } \\
\text { Barreto (2009), Nóvoa (1995), Silva } \\
\text { (2000), Tardif (2000, 2014), }\end{array}$ & 9 \\
\hline $\begin{array}{l}\text { Promoção do conhecimento sobre o } \\
\text { que o professor ensina. (D) }\end{array}$ & $\begin{array}{l}\text { Brzezinski (2008), Fusari (1992), Pinto } \\
\text { (2008), Tardif }(2000,2014)\end{array}$ & 5 \\
\hline $\begin{array}{l}\text { Promoção de visão sobre o lócus } \\
\text { onde se dá a prática do professor } \\
\text { (instituição e equipe). (E) }\end{array}$ & $\begin{array}{l}\text { Chamon (2006), Fusari (1992), Gatti e } \\
\text { Barreto (2009), Pinto (2008), Tardif e } \\
\text { Lessard (2014). }\end{array}$ & 5 \\
\hline $\begin{array}{l}\text { Valorização e reconhecimento dos } \\
\text { saberes, valores, crenças, experiência } \\
\text { e trajetória profissional dos }\end{array}$ & $\begin{array}{l}\text { Candau (2003), Gatti (2003), Gatti e } \\
\text { Barreto (2003), Nóvoa (1995), Silva } \\
\text { (2000), Tardif e Raymond (2000), }\end{array}$ & 8 \\
\hline
\end{tabular}




\begin{tabular}{|l|l|c|}
\hline professores. (F) & Imbernón (2009, 2010) & \\
\hline $\begin{array}{l}\text { Fortalecimento da identidade } \\
\text { profissional do professor. (G) }\end{array}$ & $\begin{array}{l}\text { Chamon (2006), Gatti (2003), Gatti e } \\
\text { Barreto (2009), Imbernóm (2009, } \\
\text { 2010), Nóvoa (1995), Silva (2000) }\end{array}$ & 7 \\
\hline $\begin{array}{l}\text { Promoção da compreensão do } \\
\text { contexto em que o professor, a escola }\end{array}$ & $\begin{array}{l}\text { Gatti e Barreto (2009), Imbernóm } \\
\text { e o aluno está inserido (H) }\end{array}$ & \\
\hline $\begin{array}{l}\text { Articulação entre os variados saberes } \\
\text { do professor e relação entre teoria e e } \\
\text { prática (I) }\end{array}$ & $\begin{array}{l}\text { Brzezinski (2008), Candau (2003), } \\
\text { Gatti e Barreto (2009), Imbernóm } \\
\text { (2009, 2010), Nóvoa (1995), Pinto }\end{array}$ & \\
\hline
\end{tabular}

Fonte: elaborado pelos autores.

Conforme se pode observar, as temáticas (meta-requisitos) podem ser hierarquizadas segundo o número de referências que lhes fazem menção:

1 Promoção da troca entre pares e do trabalho coletivo. (10 referências).

2 Reconhecimento da relevância da prática do professor. (9 referências).

3 Articulação entre os variados saberes do professor e relação entre teoria e prática. (9 referências)

4 Valorização e reconhecimento dos saberes, valores, crenças, experiência e trajetória profissional dos professores. (8 referências).

$5 \quad$ Fortalecimento da identidade profissional do professor. (7 referências).

6 Promoção da compreensão do contexto em que o professor, a escola e o aluno está inserido. (6 referências).

7 Promoção da compreensão das relações entre a sociedade, suas transformações e a educação. (6 referências).

8 Promoção de visão sobre o lócus onde se dá a prática do professor (instituição e equipe). (5 referências).

9 Promoção do conhecimento sobre o que o professor ensina. (5 referências).

Essas foram as categorias de análise apriorísticas advindas do procedimento metodológico acima compartilhado. Para a análise das entrevistas, valorizou-se as cinco primeiras categorias por se constituírem nas mensagens mais fortes, requisitos de formação continuada valorizados pela maior parte das referências estudadas.

\section{CONSIDERAÇÕES FINAIS}

O propósito desse artigo foi o de mostrar o caminho percorrido para a proposição de categorias de análises apriorísticas que contribuíssem com a análise de percepções de professores da educação básica, sobre práticas de formação continuada. Selecionou-se artigos pertinentes por meio de busca no Scielo e leitura dos resumos. Essas referências foram estudadas, permitindo a elaboração de um quadro, com indicações de requisitos de uma formação continuada efetiva advindas de cada referência estudada. Em seguida, aproximouse, em termos de conteúdo, tais mensagens, chegando-se a meta-requisitos, grandes temas que classificam requisitos que se aproximam, e que contribuem para reflexões sobre como deveriam ser as formações continuadas. Quantificando-se o número de referências que 
apresentarem mensagens que serviram de base para a formação de cada meta-requisito, chegou-se àqueles mais sustentados pela literatura. Este procedimento evidenciou-se uma forma plausível para se analisar percepções de professores sobre processos de formação continuada, tendo sido eleitas as seguintes categorias apriorísticas advindas de bases teóricoconceituais: promoção da troca entre pares e do trabalho coletivo; reconhecimento da relevância da prática do professor; articulação entre os variados saberes do professor e relação entre teoria e prática; valorização e reconhecimento dos saberes, valores, crenças, experiência e trajetória profissional dos professores; e fortalecimento da identidade profissional do professor.

\section{REFERÊNCIAS}

BARDIN, L. Análise de conteúdo. Lisboa: Edições 70, 1977.

BRZEZINSKI, I. Políticas contemporâneas de formação de professores para os anos iniciais do ensino fundamental. Educ. Soc., Campinas, v. 29, n. 105, p. 1139-1166, Dec. 2008 . Available from $\quad<$ http://www.scielo.br/scielo.php?script=sci_arttext\&pid=S0101 73302008000400010\&lng=en\&nrm=iso >. access on 23 Apr. 2018. http://dx.doi.org/10.1590/S0101-73302008000400010.

CANDAU, V. M. F. A formação continuada de professores: tendências atuais. In: REALI, A. de M. R.; MIZUKAMI, M. da G. N. (Orgs). Formação de professores: tendências atuais. São Carlos: EDUFSCar, 2003. p. 139-152.

CHAMON, Edna Maria Querido de Oliveira. Um modelo de formação e sua aplicação em educação continuada. Educ. rev., Belo Horizonte, n. 44, p. 89-109, Dec. 2006. Available from <http://www.scielo.br/scielo.php?script=sci_arttext\&pid=S010246982006000200005\&lng=en\&nrm=iso > access on 23 Apr. 2018. http://dx.doi.org/10.1590/S0102-46982006000200005.

DAVIS, C. L. F. et al. Formação continuada de professores em alguns estados e municípios do Brasil. Cadernos de Pesquisa, São Paulo, v. 41, n. 144, dez. 2011. Disponível em: http://publicacoes.fcc.org.br/ojs/index.php/cp/article/view/77/89

DUARTE, R. Entrevistas em pesquisas qualitativas. Educar, n. 24, p. 213-225, 2004.

FUSARI, J. C. A Formação Continuada de Professores no Cotidiano da Escola Fundamental. Série Ideias, São Paulo, FDE, v. 12, p. 25-34, 1992. 
Formação continuada de professores: a questão psicossocial. Cadernos de Pesquisa, São Paulo, n. 98, p. 191-204, 2003. Disponível em: http://www.scielo.com.br/pdf/cp/n119/n119a10.pdf

; BARRETO, E. S. S. Professores do Brasil: impasses e desafios. Brasília: UNESCO, 2009.

IMBERNÓM, F. Formação docente e profissional: formar-se para a mudança e a incerteza. 7. ed. São Paulo: Cortez, 2009.

IMBERNÓM, F. Formação continuada de professores. São Paulo: Artmed, 2010.

PINTO, C. B. G. C. A formação contínua do professor e o sucesso do ensino-aprendizagem. Universitas Humanas, v. 2, n.1. p. 408-412, 2008.

SILVA, A. M. C. A formação contínua de professores: uma reflexão sobre as práticas e as práticas de reflexão em formação. Educação \& Sociedade, n. 72, p. 89-109, 2000.

TARDIF, M. Saberes Profissionais dos Professores e Conhecimentos Universitários: elementos para uma epistemologia da prática profissional dos professores e suas consequências em relação à formação para o magistério. Revista Brasileira de Educação. ANPED, São Paulo, n. 13, p. 5-24, jan./abr. 2000. Disponível em: <http://www.anped.org.br/rbe/rbedigital/RBDE13/RBDE13_05_MAURICE_TARDIF.pdf>. Acesso em: 15 nov. 2011.

TARDIF, M. Saberes docentes e formação profissional. Rio de Janeiro: Vozes, 2014.

TARDIF, M; RAYMOND, Danielle. Saberes, tempo e aprendizagem do trabalho no magistério. Educ. Soc., Campinas, v. 21, n. 73, p. 209-244, dez. 2000. Disponível em $<$ http://www.scielo.br/scielo.php?script=sci_arttext\&pid=S010173302000000400013\&lng=pt\&nrm=iso>. acesso em 23 abr. 2018 . http://dx.doi.org/10.1590/S0101-73302000000400013.

; LESSARD, C. $O$ trabalho docente: elementos para uma teoria da docência como profissão de interações humanas. Petrópolis, RJ: Vozes, 2014. 
Recebido em:28/10/2017

Aceito em: 23/01/2018 